\title{
Blood lead concentrations among pediatric patients with abdominal pain: a prospective cross-sectional study
}

\author{
Amirhossein Hosseini ${ }^{1}$, Anahita Fayaz ${ }^{2}$, Hossein Hassanian-Moghaddam ${ }^{3,4^{*}}$, Nasim Zamani ${ }^{3,4}$, \\ Seyed Kaveh Hadeiy ${ }^{3}$, Narges Gholami ${ }^{5}$, Naghi Dara ${ }^{1}$, Katayoun Khatami ${ }^{1}$, Pejman Rohani ${ }^{1}$ and Scott Phillips ${ }^{6}$
}

\begin{abstract}
Background: Lead exposure is one of the most menacing of environmental exposures, particularly in children. Children are more susceptible to the effects of lead which manifest in many organ systems, including interference with mental and motor development. Lead poisoning can cause colicky abdominal pain. In this study, the authors sought to evaluate the prevalence of elevated blood lead level (BLL) and its contributing factors among pediatric patients presenting with abdominal pain. An epidemic of lead poisoning in adults was previously uncovered, and thus a concern for pediatric lead poisoning was raised.
\end{abstract}

Methods: Pediatric patients presenting to two pediatric clinics in Tehran with abdominal pain were eligible for enrollment in a descriptive prospective cross-sectional study. A predesigned questionnaire was filled for each patient by their consenting parents. The questionnaire queried demographic information, environmental, social, and other relevant parameters for lead exposure. After completion of the questionnaire, biometrics were obtained, and a blood sample was taken from each patient for measurement of BLL and complete blood count.

Results: A total of 187 patients were enrolled in the study. Of them, almost $20 \%$ had BLL $\geq 5 \mu \mathrm{g} / \mathrm{dL}$. Univariate analysis showed that age ( $p=0.002$, OR 3.194, Cl 95\% 1.504-6.783), weight ( $p=0.009$, OR 2.817, Cl 95\% 1.266-6.269), height $(p=0.003, \mathrm{OR} 3.155, \mathrm{Cl} 95 \% 1.443-6.899)$, and playing with both plastic and cotton toys ( $p=0.03, \mathrm{OR} 2.796, \mathrm{Cl} 95 \%$ 1.072-7.295) were significant predictors of high BLLs. Maternal level of education correlated with blood lead concentrations ( $p=0.048$, OR 2.524, Cl 95\% 1.006-6.331).

Conclusions: A clinically significant number of cases of abdominal pain may have high BLLs. Specific attention should be paid to children presenting with abdominal pain, especially due to the detrimental effects of lead on their mental and motor development.

Keywords: Lead, Abdominal pain, Pediatric

*Correspondence: hassanian@sbmu.ac.ir; hasanian2000@yahoo.com ${ }^{4}$ Department of Clinical Toxicology, Loghman-Hakim Hospital, Shahid Beheshti University of Medical Sciences, South Karegar Street, Tehran, Iran Full list of author information is available at the end of the article

\section{Background}

Lead poisoning is a common global problem and may present with abdominal pain. Lead is a greyish heavy metal. Because of lead's physical characteristics, it is vastly used in industry. Lead poisoning is counted to be one of the hazardous environmental exposures. Source for lead poisoning includes paints, water, soil, air 
pollution, old metal pipes, herbal and traditional medicines, and occupational exposures such as soldering [1].

Lead poisoning is generally asymptomatic making lead screening an important public health issue. However, neural and gastrointestinal (GI) involvement are the most common presentations. Lead poisoning has classically been reported to present with abdominal pain, constipation, nausea, vomiting, lethargy, anorexia, irritability, fatigue, and seizures [2]. It also may cause stupor, ataxia, coma, reduced IQ, anemia, nephropathy, hypertension, and infertility [1]. Although the U.S. Centers for Disease Control and Prevention (CDC) has set a blood concentration of $5 \mu \mathrm{g} / \mathrm{dL}$ as the level necessitating intervention [3], there are pieces of evidence that lead exerts its detrimental effects even in lower levels. Lead poisoning neuro-cognitive and growth impacts are special concerns [4-6]. Clinical studies of pediatric lead poisoning among Iranian children are scarce; however, several sources have been proposed including adulterated opium, soil, rice, water, dust, and air pollution [7-10].

A massive outbreak of lead poisoning happened in Iran in 2016-2017 due to adulterated opium. It is estimated that around 40,000 cases of lead poisoning occurred during this period $[8,9]$. Opium smoking with inhalation of lead particles can cause lead poisoning both in the person who smokes it and those who reside in the same place with him. This way, many children were exposed to lead particles and the frequency of lead poisoning increased in the children, as well $[11,12]$.

During the epidemic of lead poisoning in adults in Iran, the main problem was to diagnose lead poisoning in patients who referred to general emergency rooms throughout the country with non-specific symptoms including abdominal pain. Many of these patients underwent non-necessary diagnostic and therapeutic measures including laparotomy before reaching the final diagnosis of lead poisoning. This could have happened in the pediatric populations, as well. On the other hand, abdominal pain is a rather common symptom in children with different background diseases. This study aims to evaluate the prevalence of lead poisoning in children who refer with abdominal pain to two pediatric academic referral hospitals.

\section{Methods}

Pediatric patients presenting to the GI clinic of Mofid Pediatric Hospital and the pediatric gastroenterology clinic of Loghman-Hakim Hospital with the chief complaint of abdominal pain were eligible for enrollment. Those younger than 18 years of age were considered for enrollment. The goals and objectives of the study were explained to guardians, and if agreed, written consent was obtained. A pre-enrollment standardized questionnaire was provided to the parents. Questions included the patients' age, sex, weight, height, address, duration of living in their current home, age of the residential building the patients and their families resided in, history of recent renovation and painting, type of the wall paint and pipes of their home, history of playing with soil, living near industrial zones (confirmed through municipality map), type of the toys the children played with, parents' level of education and occupation, accompanying signs and symptoms with abdominal pain (e.g. nausea, vomiting, extremity pain), location and quality of the pain, onset and duration of the pain, history of previous visits for abdominal pain and treatments performed, abdominal imaging and endoscopy results and abdominal surgery (if performed), history of treatments for lead poisoning, special diet (if any), using frequent (more than 1-2 times per week) amounts of spices (e.g., turmeric's color and weight may be augmented with lead) or herbal medicine [13, 14], and presence of ice eating or pica. Findings in the abdominal examination, blood lead level (BLL), and complete blood count (CBC) results were also recorded. Blood samples were then taken, after appropriated skin preparation using ethyl alcohol, to measure BLL and $\mathrm{CBC}$. BLL was measured using the atomic absorption technique and by using Lead care II device (finger prick).

The analysis was performed using statistical package for social sciences (SPSS) software version 24 using Kolmogorov Smirnoff test to find the distribution patterns of quantitative variables, Chi square test to evaluate the differences of qualitative variables and T-test / Mann Whitney $\mathrm{U}$ test to test parametric and non-parametric quantitative variables. Cutoff points were determined using the ROC curve test for the variables which showed significant differences among patients with normal and elevated BLL. Multivariate analysis was conducted using binary logistic regression by entering variables with $\mathrm{P}$ values less than 0.2 in the model.

\section{Results}

Of the 187 patients who were entered into the study, 101 (54\%) were female. The median age was 8 years old [IQR $4,10]$ (range; 1 to 18). Of them, 165 and 21 were admitted to Mofid and Loghman-Hakim Hospitals, respectively; 109 (58.3\%) reported Tehran city as their address and other 78 (41.7\%) were either from other provinces or did not answer to the question. Figure 1 shows the distribution of patients referred from Tehran city. The onset of the abdominal pain was acute in $7(3.8 \%)$, chronic in $76(41.1 \%)$, and cyclic in $102(55.1 \%)$ patients. Thirty-six cases (19.3\%) had BLLs higher than $5 \mu \mathrm{g} / \mathrm{dL}$ and eight (4.3\%) had BLLs over $10 \mu \mathrm{g} / \mathrm{dL}$. Complete blood count results have been depicted in Table 1 . 


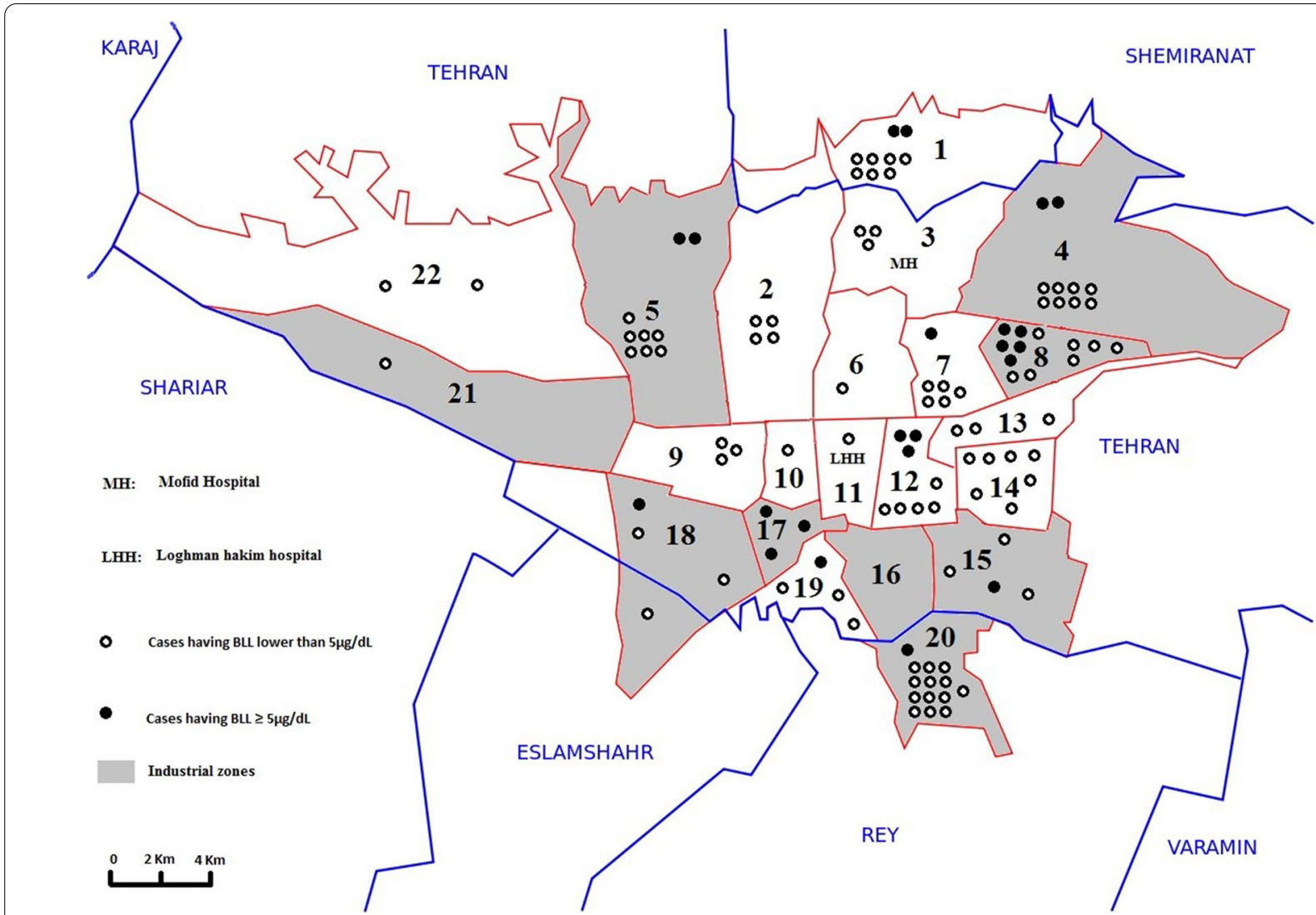

Fig. 1 High Lead level distribution in Tehran city $(n=109)$

Table 1 CBC results of the patients

\begin{tabular}{|c|c|c|c|c|}
\hline & Patients with $\mathrm{BLL} \geq 5 \mu \mathrm{g} / \mathrm{dL}$ & Patients with normal BLL & Total & $P$ value \\
\hline \multicolumn{5}{|l|}{$W B C$} \\
\hline Mean \pm SD & $8.81 \pm 2.58$ & $8.79 \pm 2.55$ & $8.79 \pm 2.55$ & 0.86 \\
\hline Min-max & $4.29-16.8$ & $4.20-17.60$ & $4.20-17.60$ & \\
\hline \multicolumn{5}{|l|}{$R B C$} \\
\hline Mean $\pm S D$ & $4.17 \pm 0.72$ & $4.19 \pm 0.82$ & $4.18 \pm 0.80$ & 0.24 \\
\hline Min-max & $2.80-5.20$ & $2.80-5.90$ & $2.80-5.90$ & \\
\hline \multicolumn{5}{|l|}{ HCT } \\
\hline Mean $\pm S D$ & $37.95 \pm 5.09$ & $37.16 \pm 6.27$ & $37.31 \pm 6.06$ & 0.58 \\
\hline Min-max & $31.90-54$ & $25-56$ & $25-56$ & \\
\hline \multicolumn{5}{|l|}{$\mathrm{Hgb}$} \\
\hline Mean $\pm S D$ & $11.66 \pm 1.14$ & $11.56 \pm 1.46$ & $11.58 \pm 1.40$ & 0.94 \\
\hline Min-max & $9.40-13.90$ & $8.50-15.30$ & $8.50-15.30$ & \\
\hline \multicolumn{5}{|l|}{ PLT } \\
\hline Mean \pm SD & $275.40 \pm 91.75$ & $292.90 \pm 101.72$ & $289.53 \pm 99.88$ & 0.36 \\
\hline Min-max & $129-454$ & $128-702$ & $128-702$ & \\
\hline \multicolumn{5}{|l|}{ MCV } \\
\hline Mean $\pm S D$ & $80.28 \pm 6.83$ & $77.62 \pm 7.45$ & $78.13 \pm 7.39$ & 0.08 \\
\hline Min-max & $65-100$ & $54-98$ & $54-100$ & \\
\hline
\end{tabular}

Patients with normal BLL $(B L L<5)$ 
In those living in Tehran, districts 7, 12, and 17 had the highest prevalence of elevated BLL (Fig. 1).
Univariate analysis found significant differences in age, weight, height, and use of cotton and plastic toys among patients with normal and elevated BLLs (Table 2).

Table 2 Univariate analysis among patients with elevated BLL $(n=187)$

\begin{tabular}{|c|c|c|c|c|c|}
\hline Variable & Odd ratio $(95 \% \mathrm{Cl})$ & $P$ value & Variable & Odd ratio $(95 \% \mathrm{Cl})$ & $P$ value \\
\hline $\begin{array}{l}\text { Epidemiological Characteristics (yes } \\
\text { vs. no) }\end{array}$ & & & Symptoms (Yes vs. no) & & \\
\hline Gender (male vs. female) & $1.61(0.77-3.35)$ & 0.20 & Constipation & $1.23(0.54-2.83)$ & 0.62 \\
\hline Age (lower than 5 years old) & $3.19(1.50-6.78)$ & 0.002 & Withholding & $0.71(0.07-7.03)$ & 0.77 \\
\hline Weight ( $\geq 23.5 \mathrm{~kg})$ & $0.35(0.16-0.79)$ & 0.009 & Diarrhea & $1.08(0.22-5.25)$ & 0.92 \\
\hline Height $(\leq 103.5 \mathrm{Cm})$ & $3.15(1.44-6.90)$ & 0.003 & Nausea & $0.60(0.23-1.55)$ & 0.28 \\
\hline Accommodation details (Yes vs. no) & & & Vomiting & $0.60(0.23-1.55)$ & 0.28 \\
\hline Living in Tehran & $0.81(0.36-1.83)$ & 0.62 & Dark stool & $0.88(0.27-2.84)$ & 0.83 \\
\hline Recent renovation of the living place & $1.30(0.55-3.09)$ & 0.55 & Dysuria & $0.45(0.13-1.58)$ & 0.20 \\
\hline Living near to industrial zones & $0.83(0.16-4.16)$ & 0.81 & No gas passing & $1.08(0.22-5.22)$ & 0.93 \\
\hline Metal pipes used in the living place & $1.17(0.52-2.63)$ & 0.69 & Blowing & $1.66(0.54-5.11)$ & 0.37 \\
\hline Wall sleek oil colored & $0.47(0.18-1.21)$ & 0.11 & Lack of concentration & $0.70(0.18-2.72)$ & 0.60 \\
\hline Wall opaque oil colored & $0.46(0.10-2.10)$ & 0.30 & Difficult child & $0.95(0.10-8.79)$ & 0.97 \\
\hline Plastic wall pain & $1.44(0.59-3.52)$ & 0.42 & Learning disability & $1.45(0.17-12.42)$ & 0.73 \\
\hline Multicolor wall paint & $1.87(0.61-5.69)$ & 0.26 & Anemia & $0.70(0.14-3.64)$ & 0.67 \\
\hline Wallpaper & $0.83(0.09-7.37)$ & 0.87 & Heartburn & $0.95(0.25-3.56)$ & 0.94 \\
\hline Medical history (yes vs. no) & & & Headache & $1.12(0.30-4.14)$ & 0.86 \\
\hline Meconium & $0.97(0.95-0.99)$ & 0.32 & Loss of appetite & $1.73(0.62-4.81)$ & 0.29 \\
\hline Soiling & $0.99(0.98-1.01)$ & 0.62 & Muscleweakness & $0.45(0.13-1.58)$ & 0.20 \\
\hline Conduction of endoscopy (yes vs. no) & $0.43(0.18-1.06)$ & 0.06 & Pain in extremities & $0.37(0.09-1.65)$ & 0.18 \\
\hline History of intestinal surgery (yes vs. no) & $0.95(0.10-8.79)$ & 0.97 & Paresthesia & $0.99(0.98-1.01)$ & 0.62 \\
\hline History of abdominal imaging (yes vs. no) & $0.91(0.34-2.42)$ & 0.84 & Hearing or visionary impairments & $0.98(0.96-1.00)$ & 0.39 \\
\hline $\begin{array}{l}\text { History of abdominal sonography (yes } \\
\text { vs. no) }\end{array}$ & $1.02(0.44-2.36)$ & 0.97 & Muscle pain & $0.22(0.04-1.15)$ & 0.05 \\
\hline Personal habits (yes vs. no) & & & Bone pain & $0.95(0.19-4.68)$ & 0.95 \\
\hline Soil playing & $0.94(0.39-2.26)$ & 0.89 & Acute onset of abdominal pain & $0.95(0.92-0.99)$ & 0.18 \\
\hline Special diet & $0.76(0.23-2.48)$ & 0.65 & Chronic abdominal pain & $0.89(0.42-1.88)$ & 0.77 \\
\hline Frequent use of spices or medicinal plants & $1.46(0.17-12.51)$ & 0.73 & Recurrent abdominal pain & $1.35(0.64-2.85)$ & 0.42 \\
\hline \multirow[t]{2}{*}{ Pika } & $0.224(0.043-1.62)$ & 0.053 & Family issues (Yes vs. no) & & \\
\hline & & & Mothers'employment status & $0.95(0.26-3.53)$ & 0.94 \\
\hline Ice eating & $0.38(0.09-1.67)$ & 0.18 & $\begin{array}{l}\text { Mothers' educational status (school } \\
\text { diploma and above) }\end{array}$ & $1.97(0.92-4.23)$ & 0.07 \\
\hline Paint wall eating & & & $\begin{array}{l}\text { Mothers' educational status (school } \\
\text { diploma and above) }\end{array}$ & $1.97(0.92-4.23)$ & 0.07 \\
\hline Toy paint eating & $0.99(0.98-1.01)$ & 0.62 & & & \\
\hline \multirow[t]{2}{*}{ Playing with toys made of plastic } & $0.51(0.24-1.09)$ & 0.07 & & & \\
\hline & & & $\begin{array}{l}\text { Fathers' educational status (14-year school- } \\
\text { ing and above) }\end{array}$ & $1.57(0.70-3.53)$ & 0.27 \\
\hline Playing with toys made of metals & $1.33(0.41-4.34)$ & 0.64 & $\begin{array}{l}\text { Fathers' educational status (14-year school- } \\
\text { ing and above) }\end{array}$ & $1.57(0.70-3.53)$ & 0.27 \\
\hline Playing with toys made of cotton & $1.22(0.37-3.96)$ & 0.74 & & & \\
\hline $\begin{array}{l}\text { Playing with toys made of plastic and } \\
\text { cotton }\end{array}$ & $2.80(1.07-7.29)$ & 0.03 & $\begin{array}{l}\text { Positive history for parents' addiction habit } \\
\text { (yes vs. no) }\end{array}$ & $2.57(0.71-9.31)$ & 0.14 \\
\hline $\begin{array}{l}\text { Playing with toys made of plastic and } \\
\text { metal }\end{array}$ & $1.43(0.37-5.60)$ & 0.60 & & & \\
\hline Playing with toys made of plastic & $0.51(0.24-1.09)$ & 0.07 & & & \\
\hline
\end{tabular}


ROC curve test found the age of five years as the best cutoff point with the highest sensitivity and specificity. However, the logistic regression model highlighted the educational level of the mothers as a single prominent factor with a significant difference between the two groups of the study (Table 3).

This factor even showed a significant difference in a higher level of BLL (BLL $\geq 10 \mu \mathrm{g} / \mathrm{dL} ; p=0.007$, OR 1.087, CI 95\% 1.026-1.152). All eight patients with BLLs $\geq 10 \mu \mathrm{g} / \mathrm{dL}$ were mothers with more than 14 years schooling.

There were no cases of paint consumption, or other types of eating disorders (rather than what is mentioned) in the patients.

\section{Discussion}

This descriptive study was conducted to find the prevalence and contributing factors to elevated BLL among the pediatric patients presenting to two pediatric centers with abdominal pain. Among factors, age, weight, and height were significantly different between those with normal and elevated BLL.

Elevated BLL was more common in children younger than five years. This is felt to be mainly due to the children's behaviors. At this age range, hand mouth behaviors are more prominent in comparison to older children. This behavior makes lead exposure through the mucosal surfaces more probable [15].

Moreover, the current study found a significant difference in the BLL of the children who played with cotton and plastic toys. The presence of lead in low-quality plastic toys and imported toys has been always a concern. Interestingly, in the current study among, plastic toys, metal toys, cotton toys, and plastic cotton toys, only the last showed a significant connection to elevated BLL. This could be because these toys may contain lead or be contaminated with dust and pollution. This issue as well as the expression of hand mouth behaviors especially in younger children may be responsible for the elevated BLL.

Lead exposure remains a major environmental health concern. Although several measures have been legislated and conducted to eradicate environmental lead poisoning, it still occurs due to various sources including lead-contaminated candies and their wrapper [16, 17], toys [18], lead-based paints in old buildings [19], lead-polluted water [20], and air pollution [7]. The health impact of pediatric lead poisoning over the life of a child may be significant as it may interfere with the proper neural development of the children affecting their cognition, emotions, and behaviors. The US CDC has introduced $5 \mu \mathrm{g} / \mathrm{dL}$ as the threshold for interventions; however, there some evidence that even lower BLLs may exert deleterious effects on the central nervous system.

Human lead kinetics are classically (and over-simplistically) referred to as a three compartments model. These pools have an interdependence and clinicians take advantage of the metal moving between compartments with the use of chelation medications. Blood is the most labile pool with a half-life of approximately 35 days. Soft tissue is the second compartment which has a half-life of approximately 40 days [21]. The most stable compartment is in bone where lead is taken up instead of calcium. This compartment is very stable with a half-life measured in years [22]. Currently, some believe there are 20 compartments [23]. The multi-compartment models that have been proposed over the years are analyzed in detail by the US CDC [24]. Recurrent lead poisoning episodes can develop and cumulative adverse effect on the central nervous system may occur. Additionally, it has been demonstrated that lead can pass the placenta affecting the neural development of the fetus [25]. This fact makes children and pregnant women the most susceptible groups in lead toxicity.

Although the above-mentioned factors were significantly different between the groups in the univariate analysis, only the education level of the mothers was significant by logistic regression. Interestingly, children of the mothers with at least 14-year schooling certificates and university degrees had higher BLLs than noncollege educated mothers. Although in the current study employment status of the mothers showed no connection to their education level, it has been suggested that it is more probable that women with higher education levels get better employments [26]. Therefore, it could be hypothesized that educated mothers in metropolises of

Table 3 Logistic regression analysis for predicting blood lead level more than $5 \mathrm{mic} / \mathrm{dL}$

\begin{tabular}{|c|c|c|c|c|c|}
\hline Dependent variable & Independent variable & Beta & SE of beta & OR $(95 \% \mathrm{Cl})$ & $\begin{array}{l}\text { Model Significance and Nagelkerke } \\
\text { R square }\end{array}$ \\
\hline $\mathrm{BLL} \geq 5 \mu \mathrm{g} / \mathrm{dL}$ & $\begin{array}{l}\text { Educational status of the mothers (more or } \\
\text { equal than } 14 \text { years schooling) (yes vs. no) }\end{array}$ & 0.926 & 0.469 & $2.5(1.0,6.3)$ & 0.013 and 0.239 \\
\hline
\end{tabular}

$P$ values which were below 0.2 including "Playing with toys made out of plastic "Playing with toys made out of plastic and cotton"', Playing with toys made out of plastic", "Positive history for parents' addiction habit", "Mothers' educational status", "Ice eating (yes vs. no)"," "PIKA", "muscle pain”, "Acute onset of abdominal pain ", "Pain in extremities", "Pain in extremities", "performing endoscopy", "Wall sleek oil colored", "Living near to industrial zones", "age", "sex", "weight", and "height" were entered in logistic regression as can be found below 
Iran spent more time out of the home. This will predispose the lead-contaminated dust and air particles containing lead to be carried into the home environment by the mothers who are in close contact with their children. Also, it can be concluded that housekeeping mothers are more engaged in the cleaning activity in comparison to employed mothers. By removing dust, a major source of lead would be eradicated.

In addition, this study found that districts 7, 12, and 17 are the districts with the highest odds of lead poisoning. This issue is another clue on the possible role of traffic related air pollution. Tehran has a base population of 8.7 million people that increased to approximately 14 million during daytime [27]. This increases vehicle exhaust and dust since these districts are in the south and central part of Tehran which has the highest traffic flows.

In the current study, 36 patients (19.3\%) had BLL $\geq 5$ $\mu \mathrm{gr} / \mathrm{dL}$. Ataee et al. have reported that nearly half of the pediatric patients who were referred to them with abdominal pain and constipation had elevated BLL while no one in the control group had BLL $\geq 5 \mu \mathrm{gr} / \mathrm{dL}$ [28]. Maleknejad and colleagues conducted a study on the prevalence of elevated BLL among pediatric patients in the northern provinces of Iran. They reported that almost $38 \%$ of the patients had elevated BLL [29]. These odds underline the importance of GI symptoms and the need for the consideration of lead poisoning as a differential diagnosis.

In the study conducted by Hatami and assistants, BLL was checked in 7-year-old children population in Bushehr province of Iran in the first grade of the primary school. About $36 \%$ had BLL $\geq 5 \mu \mathrm{gr} / \mathrm{dL}$. The interesting fact is that Bushehr province is one of the country zones with a low level of lead pollution [30]. In another study, Hosein Zadeh and coworkers evaluated the prevalence of elevated BLL among 144 random elementary students in one of the most polluted districts of Tehran. They reported that nearly $32 \%$ of the cases had BLL $\geq 5 \mu \mathrm{gr} / \mathrm{dL}$ which shows a slightly higher risk compared to the current study [31]. This rate is far higher than that observed among US children immigrants which is almost 20\% [32]. This highlights the need for implantation of screening tools for BLL assessment and probable interventions. Evaluation of the pregnant mothers in their first trimester of pregnancy and the children after birth in annual intervals until age six provides appropriate care for these groups. It can also help build a national map identifying the areas with the highest level of lead contamination [33].

Specific attention should be paid toward the populations with lower socioeconomic status. People with low socioeconomic status may live in areas with higher lead contamination, for example in older buildings with old metal pipes and paints containing lead and they may not have the budget for the eradication of lead sources in their living environment. Also, they may not afford to seek medical care when the symptoms emerge.

\section{Limitations}

One of the major limitations of the current study is the lack of a national map on the lead pollution throughout the country. Also, no precise data is available about the severity of lead pollution among various districts of Tehran. Restriction of evaluation to two centers, and small sample size makes it difficult to evaluate an exact comparison of elevated BLL among patients from different provinces of Iran and Tehran. In addition, this study has focused on the BLL of the patients with abdominal pain and no measurement for parents to see if they are exposed to lead. Presence of a pediatric group without the abdominal pain would help making a better comparison and will be considered for the future studies.

\section{Conclusions}

This study is a reminder that lead poisoning is still a cause for pediatric abdominal pain. Age was a contributing factor to higher BLL and children less than 5 years old were more vulnerable to high BLL. However, we cannot identify causality based on this study, and exposures are multifactorial. Educated mothers may have children with high BLL. The mechanism should be elucidated if this is related to cleaning the home or it is transfer of outdoor dusts containing lead.

\section{Abbreviations}

BLL: Blood lead level; CBC: Complete blood count; CDC: Centers for Disease Control and Prevention; Cl: Confidence interval; Gl: Gastrointestinal; IQ: Intelligence quotient; OR: Odds ratio.

\section{Acknowledgements}

We are grateful to the head nurse of the Pediatric endoscopy ward at Mofid Children's Hospital, Ms. Mahbobeh Basirifar, and Ms. Leila Oroujzadeh Almas, the nurse of Pediatric Pulmonology-Rheumatology ward who cooperated in blood sampling and data collection. This study is written based of thesis written by Dr. Anahita Fayaz.

\section{Authors' contributions}

$\mathrm{AH}, \mathrm{NZ}, \mathrm{NG}$ and HHM participated in the study design. AF, ND, KK and PR participated in the acquisition and interpretation of all data. $\mathrm{KH}$ wrote the first draft of manuscript. NZ, SP and HHM critically revised the manuscript. All the authors have read the journal's authorship agreement and the manuscript has been reviewed by and approved by all named authors.

\section{Funding}

This study was funded by Shahid Beheshti University of Medical Sciences, Tehran, Iran.

\section{Availability of data and materials}

The data generated by and used in the study is available from the corresponding author upon reasonable request. 


\section{Declarations}

\section{Ethics approval and consent to participate}

All procedures performed in this study was in accordance with the ethical standards of the institutional and national research committee and with the 1964 Helsinki Declaration and its later amendments or comparable ethical standards. The study was approved by the ethics (functioning as the Institutional Review Board-IRB) committee of Shahid Beheshti University of Medical Sciences. (IR.SBMU.RETECH.REC.1397.495). Informed written consent was obtained from all children parents included in the study at interview time.

\section{Consent for publication}

Not applicable.

\section{Competing interests}

Not applicable.

\section{Author details}

${ }^{1}$ Pediatric Gastroenterology, Hepatology and Nutrition Research Center, Research Institute for Children's Health, Shahid Beheshti University of Medical Sciences, Tehran, Iran. ${ }^{2}$ School of Medicine, Shahid Beheshti University of Medical Sciences, Tehran, Iran. ${ }^{3}$ Social Determinants of Health Research Center, Shahid Beheshti University of Medical Sciences, Tehran, Iran. ${ }^{4}$ Department of Clinical Toxicology, Loghman-Hakim Hospital, Shahid Beheshti University of Medical Sciences, South Karegar Street, Tehran, Iran. ${ }^{5}$ Department of Pediatrics, Loghman-Hakim Hospital, Shahid Beheshti University of Medical Sciences, Tehran, Iran. ${ }^{6}$ Washington Poison Center, University of Colorado Anchutz Medical Campus, Rocky Mountain Poison \& Drug Safety, Denver, CO, Seattle, WA, USA.

Received: 4 February 2021 Accepted: 11 November 2021 Published online: 20 December 2021

\section{References}

1. Dapul H, Laraque D. Lead poisoning in children. Adv Pediatr. 2014;61(1):313-33.

2. Ying $X L$, Gao ZY, Yan J, Zhang $M$, Wang J, Xu J, Markowitz $M$, Yan $C H$. Sources, symptoms and characteristics of childhood lead poisoning: experience from a lead specialty clinic in China. Clin Toxicol (Phila). 2018;56:397-403.

3. Goto Y, Mandai M, Nakayama T, Yamazaki S, Nakayama SF, Isobe T, Sato T, Nitta H. Association of prenatal maternal blood lead levels with birth outcomes in the Japan Environment and Children's Study (JECS): a nationwide birth cohort study. Int J Epidemiol. 2021:50(1):156-64.

4. Min MO, Singer LT, Kirchner HL, Minnes S, Short E, Hussain Z, Nelson S. Cognitive development and low-level lead exposure in poly-drug exposed children. Neurotoxicol Teratol. 2009;31:225-31.

5. Raihan MJ, Briskin E, Mahfuz M, Islam MM, Mondal D, Hossain MI, Ahmed AMS, Haque R, Ahmed T. Examining the relationship between blood lead level and stunting, wasting and underweight-a cross-sectional study of children under 2 years-of-age in a Bangladeshi slum. PLOS ONE. 2018;13(5):e0197856.

6. Tomoum HY, Mostafa GA, Ismail NA, Ahmed SM. Lead exposure and its association with pubertal development in school-age Egyptian children: pilot study. Pediatr Int. 2010;52:89-93.

7. Karrari P, Mehrpour O, Abdollahi M. A systematic review on status of lead pollution and toxicity in Iran, guidance for preventive measures. Daru. 2012;20:2.

8. Ghane T, Zamani N, Hassanian-Moghaddam H, Beyrami A, Noroozi A. Lead poisoning outbreak among opium users in the Islamic Republic of Iran, 2016-2017. Bull World Health Organ. 2018;96:165-72.

9. Jahedkhaniki GR, Zazoli MA. Cadmium and lead contents in rice (Oryza sativa) in the North of Iran. Int J Agric Biol. 2005;7:1026-9.

10. Zamani N, Gholami N, Hassanian-Moghaddam H, Farnaghi F, Gachkar L. Factors associated with high blood lead levels in a sample of 100 children in Tehran. Clin Med Insights Pediatr. 2019;13:1-6.

11. Hanna-Attisha M, Lanphear B, Landrigan P. Lead poisoning in the 21 st century: the silent epidemic continues. Am J Public Health. 2018;108:1430.
12. Christensen K, Coons MJ, Walsh RO, Meiman JG, Neary E. Childhood lead poisoning in Wisconsin. WMJ. 2019;118:16-20.

13. Cowell W, Ireland T, Vorhees D, Heiger-Bernays W. Ground turmeric as a source of lead exposure in the United States. Public Health Rep. 2017;132:289-93.

14. Lv J, Qi L, Yu C, Yang L, Guo Y, Chen Y, et al. Consumption of spicy foods and total and cause specific mortality: population based cohort study. BMJ. 2015;351: h3942. https://doi.org/10.1136/bmj.h3942.

15. Havens D, Pham MH, Karr CJ, Daniell WE. Blood lead levels and risk factors for lead exposure in a pediatric population in Ho Chi Minh City, Vietnam. Int J Environ Res Public Health. 2018;15(93):23.

16. Goto Y, Mandai M, Nakayama T, Yamazaki S, Nakayama SF, Isobe T, Sato T,Nitta H. Association of prenatal maternal blood lead levels with birth outcomes in the Japan Environment andChildren's Study (JECS): a nationwide birth cohort study. Int J Epidemiol. 2021 Mar 3;50(1):156-164.

17. Fuortes $L$, Bauer E. Lead contamination of imported candy wrappers. Vet Hum Toxicol. 2000:42:41-2.

18. Kumar A, Pastore P. Lead and cadmium in soft plastic toys. Curr Sci. 2007:93:818-22.

19. Levin R, Brown MJ, Kashtock ME, et al. Lead exposure in U.S. children, 2008: implications for prevention. Environ Health Perspect. 2008;116:1285-93.

20. Wilkinson M. Kid's lead levels high in many Michigan cities. Bridge Magazine, The Detroit News, (cited 2018 Mar 18 Available from: http://www. detroitnews.com/story/news/michigan/flint-water-crisis/2016/01/27/ many-michigan-cities-higher-leadlevels-flint/79438144/.

21. Rabinowitz MB, Wetherill GW, Kopple JD. Kinetic analysis of lead metabolism in healthy humans. J Clin Invest. 1976;58:260-70.

22. Goldman $\mathrm{RH}$, White $\mathrm{R}$, Kales $\mathrm{SN}$, et al. Lead poisoning from mobilization of bone stores during thyrotoxicosis. Am J Ind Med. 1994;25:417-24.

23. Leggett RW. An age-specific kinetic model of lead metabolism in humans. Environ Health Perspect. 1993;101:598.

24. Abadin H, Ashizawa A, Stevens YW, Llados F, Diamond G, Sage G, Citra M, Quinones A, Bosch SJ, Swarts SG. Toxicological profile for lead. Atlanta: Agency for Toxic Substances and Disease Registry (US); 2007.

25. Schnaas L, Rothenberg SJ, Flores MF, et al. Reduced intellectual development in children with prenatal lead exposure. Environ Health Perspect. 2006;114:791-7.

26. Yousefy A, Baratali M. Women, employment and higher education schoolings. Proc Soc Behav Sci. 2011;15:24

27. Hassanian-Moghaddam H. An educational and research opportunity for the largest university hospital poison control centers; Tehran and Cairo. Egypt J Forensic Sci. 2013;3(2):64-5.

28. Ataee P, Ghafouri S, Nikkhoo B, Mansouri M, Gharibi F, Eskandarifar A, et al. Blood lead levels in children with chronic non-organic abdominal pain, constipation, growth retardation, and healthy children. Iran J Pediatr. 2019. https://doi.org/10.5812/ijp.86603.25.

29. Maleknejad S, Heidarzadeh A, Rahbar M, Safaei A, Ghomashpasand B. Evaluation of serum lead levels in children with constipation and normal controls in northern Iran. Iran J Pediatr. 2013;23:417-22.

30. Hatami G, Eghbali SS, Darki A, Mohebbi G, Mohebbi F, Motamed N. Serum levels of lead in 6-7 year old children in Bushehr in 2012. Iran South Med J. 2019;21:459-71.

31. Hosseinzadeh $\mathrm{H}$. Cross-sectional evaluation of blood lead level in the most polluted middle school students of Tehran. Tehran University of Medical Sciences. Medical Diploma thesis 1997. Available through: https://ganj.irandoc.ac.ir/viewer/b4e68fdb916859ab62dd8b2968df1632? sample=1, Accessed 18 Jan 2021.

32. Pezzi $C$, Lee $D$, Kennedy $L$, et al. Blood lead levels among resettled refugee children in select US States, 2010-2014. Pediatrics. 2019;143:e20182591.

33. Neuwirth LS. Resurgent lead poisoning and renewed public attention towards environmental social justice issues: a review of current efforts and call to revitalize primary and secondary lead poisoning prevention for pregnant women, lactating mothers, and children within the U.S. Int J Occup Environ Health. 2018;24:86-100.

\section{Publisher's Note}

Springer Nature remains neutral with regard to jurisdictional claims in published maps and institutional affiliations. 